\title{
Inner Communications Following the Near-Death Experience
}

\author{
Mitchell B. Liester, M.D. \\ Colorado Springs, $\mathrm{CO}$
}

ABSTRACT: Inner communications following the near-death experience (NDE) have been reported by a number of authors. Although such communications are similar in some ways to the hallucinations heard by individuals with mental illness, they differ in that their effects are predominantly positive, whereas the hallucinations in mental illness exert predominantly negative effects. This article describes three individuals who reported experiencing inner communications subsequent to their NDEs. I suggest that these inner messages may be a form of intuition, and encourage further research into this phenomenon.

Contact with deceased relatives, friends, and incorporeal beings during near-death experiences (NDEs) has been reported by a number of investigators (Moody, 1975; Morse and Perry, 1992; Ring, 1980). Such contact with "nonphysical beings" has been likened to the interactions between children and imaginary playmates (Blackmore, 1993), attributed to defensive attempts to reduce fears of impending death (Stevenson and Greyson, 1979), and compared with hypnagogic and hypnopompic phenomena (Stevenson and Greyson, 1979).

Often these interactions are labeled "hallucinations" (Siegel, 1980), which is consistent with the American Psychiatric Association's definition as "A sensory perception that has the compelling sense of reality of a true perception but that occurs without external stimulation of the relevant sensory organ" (American Psychiatric Association, 1994, p. 767). Additional support for this characterization comes from the fact that many conditions known to precipitate hallucinations,

Mitchell B. Liester, M.D., is a psychiatrist in private practice. Reprint requests should be addressed to Dr. Liester at 6165 Lehman Drive, Suite \#101, Colorado Springs, CO 80918. 
including sensory deprivation (Zuckerman, 1970), alterations in temporal lobe functioning (Slade, 1988), and metabolic disorders (Baldwin, 1970; Reus, 1986), may occur at the time of death. Such associations have lead one author to propose a "dying brain hypothesis" of NDEs (Blackmore, 1993).

Regardless of the interpretations one places upon these messages, it is apparent that such communications sometimes continue long after the NDE has ended. Melvin Morse found that 12 percent of his subjects continued to have regular contact with the same guardian angels they saw during their NDEs, and more than 10 percent reported seeing "ghosts or other apparitions" following their NDEs (Morse and Perry, 1992, p. 164). These findings are particularly interesting given the fact that one of the inclusion criteria for participation in Morse's study was the passage of at least ten years since the NDE occurred.

This paper examines the inner communications that followed NDEs in three individuals.

\section{Methods}

All three subjects were known by the author prior to this study. A semi-structured interview was carried out with each subject during which the Near-Death Experience Scale (Greyson, 1983) was administered and the subject was asked to describe her NDE as well as the effects of the inner communications that followed the NDE. The latter questions were drawn from a prior study by Laura Miller, Eileen O'Connor, and Tony DiPasquale (1993), which investigated psychiatric inpatients' attitudes towards their hallucinations. The questions asked in the present study are as follows:

\section{General}

Would you rather keep on hearing the voices or have them go away?

\section{Controlled}

If you could control when the voices came and when they didn't, would you want to be able to hear them sometimes? 


\section{Self-Soothing}

Is there anything comforting about the voices? Anything distressing? threatening? soothing?

\section{Self-Concept}

Does hearing the voices affect the way you feel about yourself? How you compare yourself to others? Does it make you feel singled out or special?

\section{Companionship}

Do the voices keep you company when you're lonely? Do they make you more lonely?

\section{Defensive}

Do the voices protect you from uncomfortable situations or feelings? Do they warn you of danger? Do they create uncomfortable situations, feelings, danger?

\section{Reactions of Others}

How do you feel about the way other people react toward your voices?

\section{Performance}

When the voices come while you're working on something, do they affect your ability to work? Do they make your work harder or easier?

\section{Relationships}

Has hearing the voices affected your relationships with other people? If so, how?

\section{Financial}

Do you think your financial situation would be different if you did not hear the voices? If so, how? 


\section{Sexual}

Do the voices interfere with or enhance your sexual interest/activity?

\section{Case Histories}

\section{Case History \#1}

Ms. A is a 40-year-old licensed minister who suffered a cardiac arrest as a 21-year-old college student. Awakened early one morning with nausea and vomiting, Ms. A soon developed stiffness in her arms and a "grabbing" pain in her chest. Aware that something was seriously wrong, she called out to her boyfriend: "I think I'm having a heart attack!"

He incorrectly believed she was having a bad dream, and ignored her plea for help. Ms. A stated: "The next thing I realized, I was watching my body one to two feet above my body." She had never even heard of an out-of-body experience, and therefore she found the experience disconcerting: "I didn't know what to do. . . . It was an out of control experience."

Ms. A was then met by "a presence," which was "nothing I could see." She said about this presence: "It knew me and I felt comfortable with it. . . . My emotions were immediately altered by being with it. Something else was directing me. . . . It felt older than me. It had an authority to it." Describing her contact with this presence, Ms. A said: "I didn't hear anything," and "It didn't say anything." Instead, she described the communication as "sentient" or "conveyed energy transmission."

The next thing Ms. A experienced was a life review, which "seems like it took about seven seconds." This life review was described as being "like a Rolodex of my life," and she explained further: "It was like when you scroll through a computer screen." She realized from this life review that "I had been very hard on myself and that I blamed myself for everything that happened in my life. . . . I felt better instantly. . . . I felt resolved about a lot of my past."

Next, Ms. A became aware of "a small group of presences." These had distinguishing characteristics; that is, some were male and some were female, and some had "color tones." She said of these presences:

They were [there] to create a comfort zone because of what began to happen. I began to feel very light, uplifted. Then it went to ecstatic. What I realized was I didn't have any control [of the expe- 
riencel. I was being turned toward a tunnel. . . . There were more and less distinguishable presences. They were all becoming one. We were in the light. It was ecstasy beyond anything I'd ever felt. . . . It was like I was in a wind tunnel; like there was a magnet between my heart and the tunnel. They had to tell me: "You have a choice now" - staying here or going back into my body. They began to explain: "You have three things to accomplish." There was no pressure associated with this.

Ms. A stated: "There was a purpose for me being here."

Next, she received another message: "I had three seconds, then I wouldn't be able to go back." She was told: "If you don't go back now, then you can just get another body and complete these tasks another time." Ms. A decided to return to her body, and "before I knew it, I was back in a painful body. I could feel chest pain. All these people were over me."

During the time she was "unconscious," Ms. A's boyfriend awakened to find her without a pulse and he then called the paramedics. By the time she "awoke" on a stretcher, Ms. A had been without detectable vital signs for 36 minutes.

Ms. A was subsequently taken to a hospital for medical tests. Her doctor said that her electrocardiogram (EKG) "looks like a 55-year-old woman who has had a massive coronary." However, within one year her EKG had returned to normal.

During the last 20 years, Ms. A has continued to receive inner communications like those she experienced during her NDE. She said of the "type of consciousness" during which she experiences these communications: "If you mentally try to grab it and take it into your ego, it's gone." Ms. A said that these communications manifest in one of three ways:

Auditory. This voice is always heard inside her head. It is similar to a thought, but has a "knowing character": "Sometimes it feels outside of myself and sometimes there's something outside booting up your own awareness, pulling up something you already know." The voice is neither male nor female.

"Energetic." Ms. A stated that at times her body will "all at once gear up when I didn't want it to." She described one example when her hand "want[ed] to go somewhere" without her consciously willing it to. During this type of experience, Ms. A feels "more energized." She sometimes receives information about another person she's with, such as that the person is upset, and she knows what would be help- 
ful to that person. Ms. A said she can "regulate" this experience, that is, turn it off when she chooses.

Dreams. Ms. A said that she will sometimes "receive lessons energetically" in her dreams. Although she said that her dreams have become more "boring" since her NDE, sometimes she experiences "energy" while in the dream state. This energy relates to something very specific in the dream, which she recognizes to be an important lesson for her.

\section{Case History \#2}

Ms. B is a 48-year-old divorced white female who is self-employed as a massage therapist. At the age of 30, Ms. B underwent surgery on her mandible, after which her mouth was wired shut for six weeks. When the oral surgeon began to cut the wires, she experienced "the worst pain I'd ever experienced, including labor." Although she was given nitrous oxide, the pain intensified until finally she realized that she was either going to scream involuntarily, or she was going to stop the procedure. Ms. B said that at that point, "The whole room filled with golden light. The pain stopped, and I realized I was out of my body, up in the left corner of the room, watching them taking the wires off."

Ms. B described the light as "like the presence of another entity, person. . . . It's a golden light, but it is also a presence of a being that has another form." She described her communication with the light as follows: "The thoughts of the light came into my mind like my own thoughts do, but they were not my own. . . I know it was communication from another presence."

She then traveled through a tunnel to a place where there were several "stations." These were described as being similar to "learning centers or hospitals" where people were being "given information."

Ms. B did not remember experiencing a life review, but she saw several people who had already died. She described learning that there was a purpose for her "trip," which was to take less care of others. She was told that the Earth is working exactly as it should, "even if it makes no sense to us."

She was given a choice to stay or go back to her physical body, and was shown how her choice would affect others. Regarding this choice, she said, "I realized I had a lot of stuff to do," and she returned. 
After returning to her body, she felt "overwhelming disappointment" at being back. She said: "I was chagrined. . . . My thought was, 'I'm back in this world where we have to walk on two legs to get someplace."

Ms. B described the communications she received during her NDE as being "instant" and a form of "thought transfer." She explained: "It was as if two minds became one and their thoughts communicated in alternating order, as in one mind." Furthermore, she said that the communications were the most important part of her NDE, and referred to them as "life lessons."

Ms. B reported that, following her NDE, the communications never stopped. She said that she can become distracted and not hear the messages, but they are always available when she listens. She describes several types of inner communications:

The "voice of the presence." This voice is described as "a feeling of a vibration from the heart area, causing recognition and an acceptance within myself." Ms. B said that this communication is "the dearest and the purest and the most holy."

Voices that speak English. These voices sometimes give directions that do not have any logical basis, but lead to coincidences. As an example, she described a voice telling her to go to one grocery store rather than another; she did so, and ran into a friend she hadn't seen in 15 years but who had been trying to contact her. These voices also provide knowledge of what others are thinking.

Inner music. Ms. B stated that at times she hears parts of songs that apply to what is happening in her life, and at other times she hears "divine music that seems to have no source." This can provide her with knowledge, or alternatively the music may "poke fun at me."

Automatic writing. At times, Ms. B reported, "words will flow through me onto paper."

Automatic speech. "At times I say something I've never thought before. It's an inner voice through me saying something for someone else. At such times, I learn by hearing what I say and considering the meaning of it."

\section{Case History \#3}

Ms. C is a 31-year-old divorced white female, who works as a nurse in a medical office. She has the distinction of having experienced three NDEs, the first of which occurred when she was just a child. 
At the age of 6, Ms. $\mathrm{C}$ was admitted to a hospital for exploratory surgery to look for the cause of a 60 percent hearing loss in her right ear. On the day of surgery, one of the nurses administered a preoperative injection of Demerol (meperidine) and Valium (diazepam) before Ms. C was transported to the operating room. This nurse failed to note in the chart that these medications had been given, however, and when Ms. C arrived in the operating room, a second injection was administered. Aware that she had been overdosed, Ms. $\mathrm{C}$ tried to tell her doctor what had happened, but by this time, she was already too sedated to speak coherently.

As the mask was placed over her face to begin the general anesthesia, Ms. $\mathrm{C}$ felt herself leaving her body. During this out-of-body experience, she saw her EKG change to a flat line, and she watched as the operating room staff began resuscitation efforts on her body. Ms. C had suffered a cardiac arrest.

One of her first thoughts after leaving her body was: "My mom is going to be so angry with these people." As soon as she had this thought, she immediately found herself in the hospital waiting room with her mother. She watched as a man came into the waiting room and said: "We've got a problem. She had a cardiac arrest." The next thing Ms. C remembered was waking up.

Immediately after this episode, Ms. C was aware that there was "something or someone I could talk to." She said, "I could ask questions and get the answers." These answers came in the form of an inner voice that she heard inside her head. Ms. $C$ described this voice in a number of ways, including a "parental voice," a "teaching voice," and an "authoritarian voice." She said it felt "totally natural" to hear this voice, and for many years she did not realize that she was different from others who did not hear such a voice.

Ms. C said that the communications from this voice are in a "universal language." The voice does not always speak "English per se," but acts as "an imprint that comes from mind to mind."

At the age of 8, Ms. C suffered a second NDE. Hospitalized for blood in her urine, she underwent a kidney biopsy to determine the cause of this problem, but during the procedure, her portal vein was inadvertently punctured. Both she and her parents were warned upon discharge from the hospital that she should have very limited activity, but instead, she went home and went tree climbing. Two days later, she awoke in a "pool of blood."

Following her readmission to the hospital, Ms. C was transfused with several units of blood. These transfusions were likely the source 
of the hepatitis virus that she contracted, which led to a rapid deterioration in her medial condition. Her liver was severely distended and she became jaundiced. Due to her critical and worsening condition, it was decided that she should be a "no code," that is, that she should not be resuscitated if her heart were to stop.

One night soon thereafter, Ms. C told her mother, "I'm gonna go," and before long she was once again out of her body. She saw a tunnel and "I knew to head for the tunnel." She remembers a "comforting" feeling in the tunnel, which was unusual for her since the tunnel was very dark and she was afraid of the dark. At the end of the tunnel she saw a light, which she described now as the "god force." After leaving the tunnel, she met a "guy" dressed in a burlap robe, and she asked him, "Are you Jesus?" He stated he was not Jesus, but he did not identify himself, other than to say that he was there to "assist" her.

Ms. C then held a conversation with this being. They discussed the fact that death is a choice, and she could decide whether she would stay in this realm or go back to her body. She remembered that during this conversation she could look back through the tunnel and see her mother in the hospital. She said "they made me" feel her mother's emotion.

She was then told that her liver could be "fixed," but her kidneys wouldn't be repaired, due to the fact that her renal problems were a "karmic carryover" that were destined to remain with her. She then talked with this being about her path in life. She promised that she would be a nurse, and at some point when she got older, she would "gather information and share it with others." She said that she was assured that in return for this promise, she would always be able to communicate with "the other side." She was also assured that upon her "true death" she would return to the same place, as all beings go there, no matter who they are or what they have done in their physical life, "be they murderer or nun."

After she awoke in her body, one of the first things Ms. C did was look down and realize "my tummy was flat." She thought to herself, "That's quick," referring to the rapid healing of her liver. The medical staff was amazed as well by her unusual and unexpected recovery and they were at a loss to explain what had happened. Her mother was asked if someone had "given her something." On the day after her NDE, laboratory studies found no evidence of the hepatitis antibody. Years later she was again tested and still no antibodies were detected. 
Following this second NDE, Ms. C recognized, "that's when I was really different." She realized that she would "get answers" that her peers wouldn't. She continued to hear an inner voice, but stated that it was now "even more clear and believable" than after her first NDE. She said about the information she received from her inner voice: "The information just imprints on you. You're just exposed to it."

At the age of 20, Ms. C experienced a third NDE. On Christmas Eve, 1985, she developed severe abdominal pain and went to a local emergency room for help. While lying there in pain, she recognized that she was dying, and told her mother so. After an ultrasound showed blood in her abdomen, Ms. C was taken to the operating room, where a ruptured ectopic pregnancy was discovered.

While in the operating room, Ms. C was again out of her body, even before the anesthesia mask was placed over her face. This time, she hovered below the ceiling, and was met by a "guide" who did not identify herself. Ms. C remembers that it had a "female feeling," and she described the guide as being "like an angel."

She then held a conversation with this guide, who said to her: "When you were 8 and dying, you said before you died, 'I want to grow up, get married, be a nurse, and be a mommy.' Do you want anything else?"

"Yes," Ms. C replied, "I want to stay a nurse and raise that child," referring to her son, who was 11 months old at that time. She was then told, "We want you to teach people when they come into your path that they need to be very aware of what they pray for, and they need to keep the big picture in mind." Ms. C then awoke and recovered from surgery.

Since her three NDEs, Ms. C has been in communication with a number of inner voices. These include the "guides" she encountered during her NDEs and other guides she has met since her NDEs, as well as spirits of the deceased. These communications occur in three ways:

An inner voice. This is the most common. The voice is neither male nor female, and is heard inside her head. The voice never identifies itself.

Automatic writing. Ms. C said that at times she finds herself writing notes to herself, although she has no conscious awareness of this process. Interestingly, these notes refer to Ms. C in the third person.

$A$ method of communication that Ms. C calls "charades." She said that at times she experiences emotions that are out of context. She 
can "feel" these emotions inside her head and then she learns what the emotions are attempting to communicate to her.

Ms. C said that following her first NDE, these inner communications occurred at a frequency of weekly to daily. As she has become more receptive to the guidance, however, it has increased in frequency and now it occurs constantly.

\section{Interview Responses}

The three subjects described in this study experienced a total of five NDEs. On the NDE Scale (Greyson, 1983a), Ms. A's NDE scored 28 points; Ms. B's, 27; and Ms. C's, 13, 30, and 14. All three subjects met Bruce Greyson's criterion for having experienced an NDE, that is, a score of 7 or higher. Table 1 illustrates the subjects' attitudes toward their inner communications. The subjects' responses can be categorized as follows: 58 percent totally positive, 0 percent totally negative, 15 percent both positive and negative, and 27 percent neutral.

Table 1

Subjects' Attitudes Toward Their Inner Communications

\begin{tabular}{lcccc}
\hline & $\begin{array}{c}\text { Totally } \\
\text { Positive }\end{array}$ & $\begin{array}{c}\text { Totally } \\
\text { Negative }\end{array}$ & $\begin{array}{c}\text { Positive } \\
\text { and } \\
\text { Negative }\end{array}$ & Neutral \\
\hline General & 3 & 0 & 0 & 0 \\
Controlled & 3 & 0 & 0 & 0 \\
Self-soothing & 0 & 0 & 3 & 0 \\
Self-concept & 2 & 0 & 0 & 1 \\
Companionship & 2 & 0 & 0 & 1 \\
Defensive & 2 & 0 & 0 & 1 \\
Reactions of others & 0 & 0 & 0 & 3 \\
Performance & 1 & 0 & 1 & 1 \\
Relationships & 2 & 0 & 1 & 0 \\
Financial & 2 & 0 & 0 & 1 \\
Sexual & 2 & 0 & 0 & 1 \\
Total & $\mathbf{1 9}$ & 0 & $\mathbf{5}$ & $\mathbf{9}$ \\
\hline
\end{tabular}


In general, all three subjects felt positive toward their inner communications. None described effects that were exclusively negative. All three also said they would like to be able to control when the voices came and when they did not. All three subjects described their voices as being soothing or comforting, but all three subjects said they could also be distressing. Ms. A said she found them distressing "only if I disagree or resist." Ms. B said her voices are generally comforting, but they "sometimes bring something I don't want to hear." When this occurs, she said, the information she receives is helpful, even though she initially resists it. Ms. C said she sometimes found the communications distressing because "they're honest; they're objective. What they say isn't always comforting, but they're always right." None described the voices as threatening.

Two of the three subjects described a positive influence on selfconcept, and the third described no effect on self-concept. Two subjects felt they benefitted in terms of companionship from their communications, while the third reported no effect.

All three said their inner communications have at times warned them of danger, but only two felt protected by their voices. Two of the subjects stated that they rarely tell others about their communications, which made it difficult for them to evaluate others' reactions. Ms. C stated that she feels "fine" about others reactions. She stated that she understands others don't always understand her experiences because "it's not their experience."

Regarding work performance, one subject said her communications had no effect, one described a positive effect, and the third subject stated that her work may be enhanced or hampered. The latter subject, Ms. C, works as a nurse. She described that her inner voices sometimes talk about a patient who has already left the office, making it difficult to concentrate on the current patient.

Relationships have been positively influenced by the communications of two subjects, and the third described influences that are equally positive and negative. Ms. A stated that she has become "more extroverted" and "more comfortable talking to strangers." Ms. $B$ stated that her voices "tell me what another person is thinking when I need to know it." Furthermore, she said that her voices have "made me gentler, more understanding of where the other person is." Ms. C stated: "People have turned from me, others are drawn to me." 
Two subjects reported that their communications have had a positive impact upon their financial situation, by assisting them in their work. The third subject reported no impact.

One subject described no effect on sexual relationships, while the other two reported positive effects.

\section{Discussion}

The following conclusions must be considered preliminary due to the methodological limitations of the study, including the small number of subjects involved and the nonrandom selection of subjects. However, since the results of this study are consistent with previous anecdotal reports of individuals who experience inner communications following NDEs, these conclusions may assist in the design of a larger study that could examine this phenomenon in more depth.

One criticism that has been leveled against studies investigating NDEs is that they are, of necessity, retrospective. Often these studies are carried out years, or even decades, after the NDEs occurred. This increases the possibility that important information may have been forgotten or unconsciously distorted. The inner communications described in this study provide an opportunity to explore one of the NDE-related phenomena while it is occurring.

These three cases indicate that the inner communications that follow NDEs may occur as inner voices, involuntary movements, automatic writings, automatic speech, sensations of energy or vibrations in the body, inner music, emotional reactions that are out of context for the situation, and an inner knowledge that is not attributed to the senses or the intellect.

Although the inner voices described meet the diagnostic definition of a "hallucination" (American Psychiatric Association, 1994), they exert predominantly positive subjective effects on the lives of those who hear them. This distinguishes them from the hallucinations experienced by the mentally ill, which have predominantly negative effects (Miller, O'Connor, and DiPasquale, 1993). Therefore, before relegating these communications to the realm of brain pathology, as some authors have done, it would appear reasonable to consider alternative explanations for this phenomenon.

One such alternative is that this inner guidance is a form of intuition. Intuition is defined as the "direct perception of truth, fact, etc., independent of any reasoning process; immediate apprehension" 
(Webster's Encyclopedic Unabridged Dictionary of the English Language, 1989, p. 747). Accounts of intuitive inner voices have been reported for thousands of years. In fact, such voices have been heard by some of history's most revered figures, including Winston Churchill (Fishman, 1963), Mohandas Gandhi (Gandhi, 1992), Martin Luther King, Jr. (Ayres, 1993), George Washington Carver (Clark, 1939), Socrates (Jowett, 1986), Joan of Arc (Sackville-West, 1964), and Carl Jung (Jung, 1963).

Previous authors have described increased psychic abilities following NDEs (Greyson, 1983b; Kohr, 1983; Morse and Perry, 1992; Ring, 1984). One possible explanation for this increase is that NDEs may catalyze a shift in one's baseline or "normal" state of consciousness, permitting greater access to latent intuitive potentials. Such access has previously been reported to occur in altered states of consciousness (Vaughan, 1979).

If this is true, why don't all NDErs experience intuitive communications following NDEs? Perhaps different individuals reidentify with their egos to varying degrees following the NDE. Detachment from the ego has been associated with increased intuitive abilities (Wilber, 1977), indicating that the less one identifies with the ego, the greater the access to intuitive guidance.

A second and perhaps related theory has been proposed by Melvin Morse, who suggested that the right temporal lobe functions like "a receiving system, one that allows us to hear voices from a source outside our bodies" (Morse and Perry, 1992, p. 196). This interesting hypothesis is consistent with the reported relationship between intuition and the right cerebral hemisphere (Vaughan, 1979).

Regardless of whether NDE-related communications are interpreted as hallucinations or intuitions, further research into this phenomenon is certainly warranted. Previous investigators have found increased glucose metabolism in the right hemisphere (Cleghorn, Franco, Szechtman, Kaplan, Szechtman, Brown, Nahmias, and Garnett, 1992), changes in auditory evoked potentials, and altered cerebral magnetic fields (Tiihonen, Hari, Naukkarinen, Rimón, Jousmäki, and Kajola, 1992) in individuals who are actively hallucinating. Although it is not known whether NDErs experience similar physiologic changes while receiving inner communications, it would be relatively easy to design and carry out a study to find out. However, the greatest benefit from studying these communications may come not from a search for their etiology, but rather from a more complete understanding of their effects on those who hear them. 


\section{References}

Ayres, A. (Ed.). (1993). The wisdom of Martin Luther King, Jr. New York, NY: Penguin.

Baldwin, M. (1970). Neurologic syndromes and hallucinations. In W. Keup (Ed.), Origin and mechanisms of hallucinations: Proceedings of the 14th annual meeting of the Eastern Psychiatric Research Association (pp. 3-12). New York, NY: Plenum.

Blackmore, S. J. (1993). Dying to live: Near-death experiences. Buffalo, NY: Prometheus.

Clark, G. (1939). The man who talks with flowers. Shakopee, MN: Macalester Park.

Cleghorn, J. M., Franco, S., Szechtman, B., Kaplan, R. D., Szechtman, H., Brown, G. M., Nahmias, C., and Garnett, E. S. (1992). Toward a brain map of auditory hallucinations. American Journal of Psychiatry, 149, 1062-1069.

American Psychiatric Association. (1994). Diagnostic and statistical manual of mental disorders (4th ed.). Washington, DC: American Psychiatric Association.

Fishman, J. (1963). My darling Clementine: The story of Lady Churchill. New York, NY: David McKay.

Gandhi, M. (1992). All men are brothers. New York, NY: Continuum.

Greyson, B. (1983a). The Near-Death Experience Scale: Construction, reliability, and validity. Journal of Nervous and Mental Disease, 171, 369-375.

Greyson, B. (1983b). Increase in psychic phenomena following near-death experiences. Theta, 11, 26-29.

Jowett, B. (Trans.). (1986). The dialogues of Plato. New York, NY: Bantam.

Kohr, R. L. (1983). Near-death experiences, altered states, and psi sensitivity. Journal of Near-Death Studies, 3, 157-176.

Jung, C. G. (1963). Memories, dreams, reflections. New York, NY: Vintage.

Miller, L. J., O'Connor, E., and DiPasquale, T. (1993). Patients' attitudes toward hallucinations. American Journal of Psychiatry, 150, 584-588.

Moody, R. A. (1975). Life after life. Covington, GA: Mockingbird Books.

Morse, M. L, and Perry, P. (1992). Thansformed by the light: The powerful effect of near-death experiences on people's lives. New York, NY: Villard.

Reus, V. I. (1986). Behavioral disturbances associated with endocrine disorders. Annual Review of Medicine, 37, 205-214.

Ring, K (1980). Life at death: A scientific investigation of the near-death experience. New York, NY: Coward, McCann and Geoghegan.

Ring, K. (1984). Heading toward omega: In search of the meaning of the near-death experience. New York, NY: Morrow.

Sackville-West, V. (1964). Saint Joan of Arc. New York, NY: Doubleday.

Siegel, R. K (1980). The psychology of life after death. American Psychologist, 35, 911 -931 .

Slade, P. D., and Bentall, R. P. (1988). Sensory deception: A scientific analysis of hallucination. Baltimore, MD: Johns Hopkins University Press.

Stevenson, I., and Greyson, B. (1979). Near-death experiences: Relevance to the question of survival after death. Journal of the American Medical Association, 242, 265267.

Tiihonen, J., Hari, R., Naukkarinen, H., Rimón, R., Jousmäki, V., and Kajola, M. (1992). Modified activity of the human auditory cortex during auditory hallucinations. American Journal of Psychiatry, 149, 255-257.

Vaughan, F. E. (1979). Awakening intuition. New York, NY: Doubleday.

Webster's encyclopedic unabridged dictionary of the English language. (1989). New York, NY: Gramercy.

Wilber, K (1977). The spectrum of consciousness. Wheaton, IL: Quest.

Zuckerman, M. (1970). Reported sensations and hallucinations in sensory deprivation-Research data relevant to 13 hypotheses and a reformulation. In W. Keup (Ed.), Origin and mechanisms of hallucinations: Proceedings of the 14th annual 